\title{
A Phenomenological Perspective On Feminist Critique Of Reason
}

\author{
Hafiz Syed Husain \\ Department of Philosophy \\ University of Karachi \\ Mustafa Hyder \\ Department of Public Administration \\ University of Karachi \\ Mariam Sultana \\ Department of Mathematical Sciences \\ Federal Urdu University of Arts, Science \& Technology
}

\begin{abstract}
This study expounds a phenomenological perspective on feminist critique of reason. Following the lead of Nagl-Docekal, a hypothesis is reached by which a possibility is recognized that the feminist argument which is founded on gendering the unity of reason is mistaken. This gendering ultimately results in identifying the traditional manifestations of reason as a structure of oppressive power dynamics which feminist philosophy deems masculine. Although, this investigation admits that some of the main premises of feminist argument are supported by evidence, however, the main contention is that its conclusion is problematic. A phenomenology of reason is proposed, after Edmund Husserl's transcendental phenomenology, with the intention of providing support for the validity of hypothesis and offer better prospects for a critique of reason. Furthermore, It is also argued that phenomenology of reason so outlined already incorporates the valid aspects of feminist critique of reason. The methodology of this investigation is comparative-analytic. The purpose of this study is to provide a philosophical foundation for feminist critique of reason which is aimed at unmasking the illicit pretensions of the oppressive dynamics exhibited in the name of reason.
\end{abstract}

Keywords: Feminism, Critique of Reason, Transcendental Phenomenology, Masculinity of Reason.
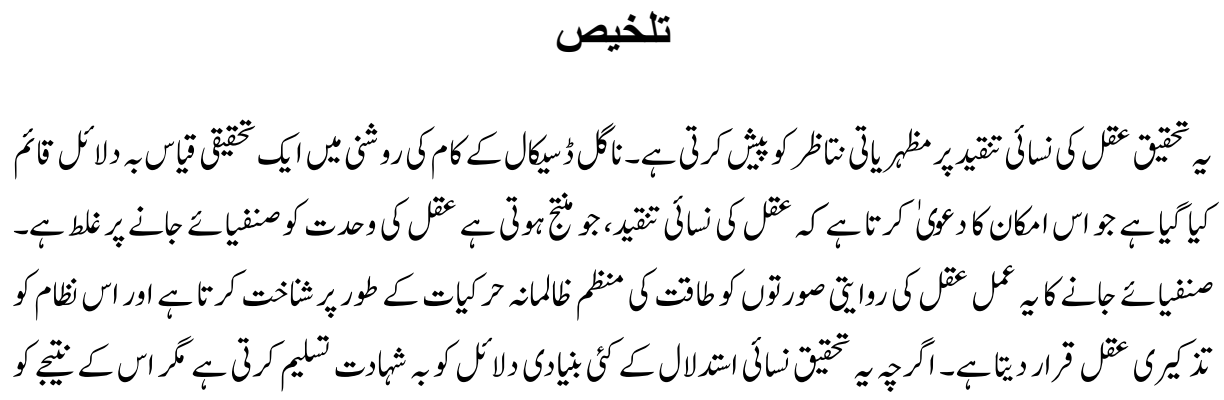


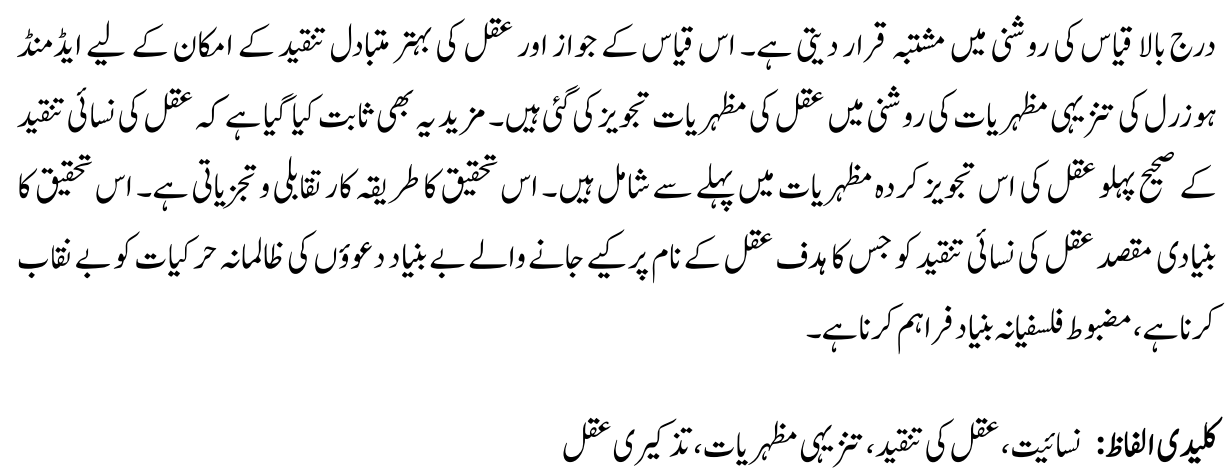

\section{Introduction}

Feminism thinking since latter half of twentieth century - especially third-wave feminism 1970 onwards - has been characterized as both, a philosophy, and a performative discourse aimed at bringing about the emancipation of the oppressed from socio-political power dynamics which is historically constituted (Zack, 2007; Alcoff, 2006). The group of the oppressed is predominantly presumed to be women, but may include all underprivileged gender groups (e.g. transgendered, eunuchs, transvestites etc.) as long as their being underprivileged is due to their problematic gender identity (Fisher, 2011). Patriarchy conceptually designates this power-dynamics. Although, the emancipatory socio-political side is always the ultimate goal that is aimed at as the result of feminist discourse, but its philosophical aspects are comparatively more contentious. One main reason why this is the case follows from the presumption that philosophical method involves its foundation in the faculty of human reason (Logos) which feminists deem masculine, and thus should be considered the cause of the problem itself instead of providing direct help for a solution (Irigaray, 1985, pp. 72ff, 99ff). This problem could be remedied only by a proper feminist critique of reason (Logos) that would subvert its implicit masculinity with the expectation that such a critique would render the possibility of a coherent feminist philosophy (Nagl-Docekal, 1999). Precedents of such a critique include Evelyn Fox Keller's (1995) deconstructive reading of Francis Bacon's writings, Luce Irigaray's (1985) psychoanalytic interpretation of Greek Logos as what guides the Western reason-in particular scientific and enlightenment reason of Newtonian and Kantian type - and Judith Butler's (1993, 1997 and 2005)indefinite differentiation of this latter's unity into what can be regarded as an enigmatic tension between the subject that is socially constructed as a result of a prior power structure and the same power structure which itself propagates dynamically through history as a result of agency (which is the very condition of the possibility of that same subject) (Halsema, 2011). Finally, we have Docekal's (1999) transcendentalist approach of this critique which aims at founding feminist philosophy coherently with Universalist democratic ends. Present study involves developing a phenomenological perspective on these critical endeavors. It will be argued that all these four critical frameworks intended to found a feminist philosophy are right in 
some aspects but also mistaken in others. ${ }^{1}$ Our reflections will involve phenomenology with the intention of working out a phenomenological demonstration for the possibility of the most primordial gender differentiation which is in a continuous dialectical tension with another most primordial principal unity such that this unity is not one of masculine type.

We can philosophically classify, as far as the critical methodology is concerned, Evelyn Keller's critique as comparatively more hermeneutic, Irigaray's and Butler's critique as what involves strong hermeneutic and phenomenological underpinnings and Docekal's critique as transcendental of Kantian type. ${ }^{2}$ Though their philosophical methodologies differ, they all agree in some of the basic tenets in historically working out the structure of power-dynamics inasmuch as it historically manifests itself in modern Western scientific rationality. The basic axiom is as follows: reason is both unitary and totalitarian inasmuch as unity and totalitarianness are the two parameters with which the oppressive dynamic power-structure (patriarchy/masculinity) has manifested itself. Here, unity implies reason's claim to universality, which as a consequence implies its claim to be gender neutral. Totalitarianness means that whatever goes against the dictates of this reason must be dispensed. This latter is the ethical demand which follows as the consequence of accepting the unity of reason. Once construed this way, it will not be difficult to assess the under representation of women in the professional fields of academia, in particular, philosophy (Zack, 2007) and mathematics. ${ }^{3}$ It is not easy to present a full reconstruction of their arguments separately, that can be philosophically demonstrated to be regressing back at this axiom, for we would then require a space not permissible within this research article. Authors refer to (Nagl-Docekal, 1999) for working out a possible reconstruction towards that axiom. ${ }^{4}$

Up to this point, there is no problem. However, as soon as we try to analyze what each of these thinkers really construe by reason combined with the method of critique with which each one pursues to subvert its masculinity, we run into some serious problematics. There is sufficient evidence that Keller takes reason to be the scientific rationality, ${ }^{5}$ Irigaray takes Greek Logos and correspondingly logic and philosophical methods of arguments aimed at positing singular reality as exemplifications of her construal of reason(Irigaray, 1985 , pp. 25ff, 72ff, 99ff). Butler's conception of reason is not so easy to pin down. As already remarked above (cf. section 1), it involves subjection that is deeply rooted in socio-historical fabric. Authors think that Butler is partly in agreement with Irigaray when it comes to the authoritative subjection which history of philosophy and scientific rationality has inflicted. Docekal does not explicitly state her conception of this oppressive reason, but it is clear that she takes the axiom to be a characterization of this reason and takes both instrumental and scientific rationality to be its exemplifications par excellence (Nagl-Docekal, 1999, pp. 67-68). This gives a comparatively stable notion of reason with scientific and philosophical rationalities as being its primary expressions. However, there is a significant difference between Docekal and the rest. Docekal does not consider all aspects of this reason's unity as being responsible for its totalitarianness. She even challenges a fundamental link (which Irigaray and Butler especially adhere to) 
between unity and universality. For instance, according to Docekal, both Butler and Irigaray are mistaken in equating Kantian categorical imperative-the regulative principal of Kant's practical reason - as being a universal with which the practical reason operates with totalitarian authority. According to her, practical reason presupposes the universality of its action through categorical imperative which is thoroughly concrete, and is thus one of hermeneutic type. ${ }^{6}$ What Docekal is implicitly claiming is that Kant shifted his position in transcendental philosophy, from his first critique - the Critique of Pure Reason-where he did have categories of reason which were universal and necessary principals with which pure reason was claimed to function, towards his second critique - the Critique of Practical Reason; and that the feminist critique commits the fallacy of overdrawn objections when they don't take this shift into account. Thus, though there is indeed a connection between the unity and totalitarianness as stated in the axiom, but that this connection is not as strong as it might appear to a feminist critique.

\section{Research Hypothesis and Question}

This shows, if Docekal is right, that the reason possesses a unity which has a dimension that is not to be confused with oppression of masculine on feminine gender; where an admission of this dimension in no way implies that the rest of the feminist critique is mistaken as well. So there is indeed an oppressive masculine dimension of reason, but first of all reason is not equal to it at all, secondly, there is another dimension such that this dimension holds the key for subverting the oppressive dimension, not by gendering it (or equivalently subverting it) by an equally totalizingfeminist critique so that a new dimension - i.e. a feminist dimension - appear to counter the oppression and make way for emancipation; but instead, by a subversion that is made possible intrinsically. In order to avoid confusion, we will name the oppressive dimension as MD, the gendering of MD which results from overdrawn feminist critique as FD and the primordial unity that escapes both the MD and FD (already remarked above) as PD. So we have the following hypothesis: feminist critique of reason is mistaken inasmuch as it has made reason equal to MD but it is valid inasmuch as it has established the existence of MD, which shows that both MD and FD are part of reason but they both cannot exhaust reason, so there must be more in reason which escapes both MD and FD.

We have used Docekal's argument only to reach the hypothesis. ${ }^{7}$ So there are two ways to prove the hypothesis and explicate the resulting structure of reason. First, we may prove that Docekal is right in her critique of the feminist critique of reason as pursued by the others. This can be done by further seconding Docekal's argument from Kant's transcendental framework. Or, take a radically different strategy such that this strategy does not negate what we have already established in this study till this point. We will follow the latter approach. To serve this end, we intend to employ the method of Husserlian phenomenology as our methodological framework - philosophically speaking. In what follows we will first introduce Husserlian phenomenology with the intention of justifying how it makes sense to use this philosophical method to investigate the validity of hypothesis. This intention coupled with hypothesis above renders our research 
question as: How phenomenology is justifiably a philosophical method to investigate the validity of our hypothesis such that it does not succumb to the valid aspects of feminist critique and become an MD itself?

\section{Towards a Phenomenological Perspective}

In what follows we employ the method of Husserlian phenomenology to ground our analysis. ${ }^{8} \mathrm{We}$ bracket the question of truth and focus on the phenomenon of reason. Since phenomenology can be characterized as the very method by which phenomenological object of investigation manifest itself through itself(Husserl, 2001, p. 168), what we are in fact talking about is working out the possibility and explication of a phenomenology of reason. But before we may advance any further, we may be required to show (i) how reason can justifiably be an object of phenomenological investigation, and (ii) what do we mean by such an object 'reason' phenomenologically speaking. We try to answer both (i) and (ii) correlatively as follows. ${ }^{9}$ There will be three different designations for reason: (a) reason, (b) 'reason' and (c) 'Reason.' Reason without quotations (i.e. (a)) refers to what ordinary language (including scientific disciplines) has to offer in context of understanding reason; 'reason' corresponds to the same reason (without quotes) under phenomenological epoché, and finally 'Reason' as what we-in this phenomenological investigation - are primarily after.

We are assuming that phenomenological method of investigation is already undertaken till the point of epoché. ${ }^{10}$ This means that we are not privileging any particular example of 'reason' over any other. As far as disciplinary manifestations are concerned, all examples are equally valid for us. So, for instance, reason, as accounted in formal and informal logic, or in mathematics (certainly not equivalent to logic after Kurt Gödel's incompleteness theorems $)^{11}$, or in epistemology or metaphysics, in theoretical physics, all social theoretic research perspectives (e.g. Marxism, psychoanalysis, symbolic interactionism, functionalism etc.), all psychological theoretic perspectives (behaviorism, biological essentialism, psychoanalysis, etc.) etc. are all taken to be exemplifying what constitutes 'reason.' This means that the feminist critique of reason is already taken to be exemplifying reason. ${ }^{12}$ After this, we proceed through transcendental reduction to achieve the transcendental attitude or perspective. It is here that we arrive at the phenomenological question: what is constitutive of this 'reason'? The answer to this question is the phenomenological object sought in the name of 'reason,' and the account of answering it also known as phenomenological demonstration is the phenomenology of reason. We will write this as 'Reason,' i.e. the constitutive principal, to differentiate it from the 'reason' and reason. Latter is the reason under natural attitude which includes not only everyday life common-sense view but also any scientific view without bracketing their semantic value. 'Reason' thus construed can never be any object of everyday-life common-sense criticism, nor can it ever be an object of investigation for any science. ${ }^{13}$ In principal, it is the constitutive principal of 'reason,' which can only be an ideal or essential structure by virtue of which all experiences involving 'reasoning' are constituted, both in everyday life and in the public life led by academia. 


\section{The Phenomenology of Reason}

The ultimate task of Husserlian phenomenology is to work out the essential or ideal conditions for the possibility of the most general type of experiences or objects. ${ }^{14}$ Following the fundamental methodological axiom - which Husserl called 'principal of all principals' we are only allowed to accept an object as evidence when it is given 'originarily' in a 'selfgivingintuition." 15 Here, self-giving intuition or originary intuition refers to the most primordial experience - phenomenologically speaking - where that object is bodily or 'in person'(in the sense of the object-itself) presented. For someone not an expert in phenomenology, this may sound quite mind-boggling, for how could one find 'Reason'which is 'reason' not as it may appear but as what it is in-itself -inan 'in person' experience? This is one of the most deeply puzzling but also one of the most significant idea that requires elaboration. Since all consciousness is always consciousness of something (or equivalently, consciousness is always directed at something) ${ }^{16}$, we find directedness (technically called intentionality) as a characterizing aspect of consciousness. ${ }^{17}$ There are two kinds of intentionalities; signitive or empty intentions, and intentions with which empty intentions are fulfilled. ${ }^{18}$ Examples of empty intention are linguistic utterances, text, a painting, a mathematical theorem or concept, etc. examples of fulfilling intention are what render empty intention their satisfaction; e.g. if the linguistic utterance was about some particular object, then the intuition with which that particular object is found gives the fulfillment of empty intention in an originary manner (i.e. experience 'in person'). In this example, ordinary perception corresponds to the originary intuition.

Above example of originary intuition (self-giving intuition) is a very special case, meant only to motivate the idea. Phenomenology is not after such elementary examples. On contrary, Husserl's phenomenology of time (1991) is an example par excellence of such an originary self-giving intuition. Here, the phenomenological object sought is 'Time'i.e. What is responsible for the constitution of 'time' or the constitutive principal of 'time'. ${ }^{19}$ It corresponded to a threefold intentional structure of 'retention-primalimpression-protention' which correlated with a double intentionality responsible for constitution of both the self and the world as being correlatively temporally extended. ${ }^{20}$ Here, 'Time' emerged through a self-giving intuition (Husserl's originary intuition) such that the phenomenological demonstration of this intentional structure was itself the selfgiving (originary) intuition and the thing-itself behind 'time' which was so achieved was this very 'Time. 'This shows that originary intuition does not have to be one of perceptual kind, but may include phenomenological clarification about some particular phenomenon. In fact, phenomenology is always after such originary intuitions (Smith, A.D., 2003, pp.45-33). Furthermore, since according to Husserl, any intentional accomplishment (constitution of any natural object; ${ }^{21}$ for instance 'reason') depends upon the temporal feature of conscious life, thus any problem of intentional accomplishment is preceded by the problem of 'how time is constituted?' (Husserl, 1991, p. 286). Since all acts of 'reasoning' are temporally extended, 'Reason' as an intentional accomplishment (within 
transcedental realm) is founded on the intentional accomplishment of the constitution of the temporal aspects of consciousness (within transcendental realm). Thus, phenomenology of 'reason' is also founded on the phenomenology of 'time' insofar as the intentional structure of the act of reason is founded on the intentional structure involved in the temporal constitution of self-consciousness.

\section{Feminists' Anti-subjectivist Stance and a Possible Objection on Husserl's Transcendental Phenomenology}

Husserl has often been accused of phenomenologically explicating phenomena from the side of the subject alone; or equivalently, that his model of intentionality is too much subject centered, voluntary and intellectualistic (Kelly, 2003). Some of these voluntary idealistic interpretations involve Husserl's misunderstood passages primarily from his Ideas-I (and other texts seen in conjunction with passages from Ideas- $I$, for instance: (Husserl, 1960, pp. 25-26; Husserl, 1983, pp. 51-53). These are considered as the Cartesian remnants in the thought of Husserl and thus form an intrinsic part of what was primarily targetedas the 'subjection of reason'-primarily by Judith Butler(cf. above sections 1-2). Butler also followed the same line of argument against Husserl and his transcendental phenomenology (Butler, 1988). ${ }^{22}$ On the other hand, she also acknowldges that feminist criticism has got a lot to learn and make use of phenomenology-especially as expounded by Merleau-Ponty (2005) - for she sees in it an opportunity to desubjectivize Husserl's phenomenology (Butler, 1988). Her motivation for this possibility lies in her analysis of feminine experience of body, where she concludes that femininity is already constituted before any self-conscious subjectivist act is able to determine it. Criticising the traditional sex vs. gender naïve distinction which regards sex as the biological fact and gender a cultural artifact, ${ }^{23}$ she claims that the matrix of gender relationship is part of the social fabric of society which holds the condition of possibility for any gendering into feminine or masculine (or another in between) (Butler, 1993, p. 7). Luce Irigaray also followed the same line of argument when she regarded bodily experiences as prior to any possibility of theorizing, which also includes subject-centered interpretation of Husserlian phenomenology (Irigaray, 2001, p. 21). Thus, gender identity has its constitutive principal which is active prior to its self-conscious realization.

\section{Overcoming the Subjectivist Reading of Husserl}

Authors have no objection on the basic feminist insight that the constitutive principal is active prior to any subjectivist autonomous act; i.e. masculinity and femininity (or any other identities in between them) are not the product of the self-conscious acts of those whose identity is involved. It is only that Husserl is misunderstood when it comes to applying his phenomenological methods and characterizing them as subject-centered. First of all, there is no singular Husserlian phenomenology. There are at least three ways with which phenomenological investigation can be initiated. There is sufficient textual evidence that Husserl talked about the 'Cartesian Way' into phenomenology and other 'two alternatives' (Smith A. D., 2003, p. 54). The 'Cartesian Way' was also called by Husserl as the 
epistemological way. Husserl did acknowledge the distinction between them but did not see them to be mutually contradictory. Butler (1988; 1993, p. 7) and others (like (Kelly, 2003) who accuse Husserl of subject-centered methodology take the 'Cartesian Way' as the only dominant way to initiate Husserlian phenomenology. They are also the ones who see Merleau-Ponty (and Martin Heidegger's phenomenology) as radical breaks from Husserl.

Again, there is sufficient textual evidence from Husserl's work which remained unpublished during his lifetime that Husserl was misunderstood as a subject-centered thinker. The primary source of this is the posthumously published work Crisis (1970). Here, one finds Husserl's conception of self, neither psychological nor metaphysically subjectivist (which Butler interpreted as the traditional metaphysical 'substance' (1988)). Husserl talks about the self (or self-consciousness) that distances itself from itself (Husserl, 1970, pp. 185-86).No Cartesian or subject-centered metaphysical understanding of 'self' can ever help us make sense of such a phenomenological description of self. As Sara Heinämaa has shown (2011), this is the point where we can see not a radical break, but a positive extension of Husserl in Ponty's motor intentionality and his phenomenology of the lived-body (Merleau-Ponty, 2005, pp. 127, 159n), something which Butler herself has acknowledged possessing prospects for a feminist critique (1988). Since genetic method which characterizes these alternative to the 'Cartesian Way' in Crisis was already implicitly presumed in the phenomenological analysis of time constitution, our phenomenology of reason, if worked along the line of non-Cartesian way will avoid Butler's (and also Irigaray’s) criticism.

Founding the phenomenology of reason on phenomenology of time does not imply deducing the intentional structure of 'reason' from the intentional structure of timeconstitution as expounded in (Husserl, 1991), for this will only fall prey to Butler's antisubjectivist critique. We must first give an account of transition from phenomenology of time to the genetic method of Crisis such that the subjectivist reading of Husserl is interpretively de-subjectivized. For this we follow the lead of Sara Heinämaa (2011). In her work "Personality, Anonymity, and Sexual Difference: The Temporal Formation of the Transcendental Ego," she argues how the triadic structure of Husserlian self as (a) transcendental ego, (b) transcendental person and (c) monad, involves a correlation that was explicated through the use of genetic method as expounded in Cartesian Meditations. ${ }^{24}$ This premise is important and must be accounted so that a transition from phenomenology of time (1991) to the Crisis can be made through Cartesian Meditations. This can help in working out the phenomenology of reason that is non-subjectivist. She establishes how the notion (or dimension) of the transcendental person involves habitualities (correlated systems of habits) which gives ego a 'style' (Gestalt) of acting. This 'style' is non-thematic, in other words, not available to psychological selfconsciousness. It further has at least two more aspects, a voluntary, and a practical. The practical dimension involves not only axiological acts but also goal-directed acts which are founded on passive synthesis of bodily-lived experiences. This includes examples which Luce Irigaray registered as the unconscious acts and experiences of touch. ${ }^{25}$ Here, most fundamental experiences of embodiment which precedes any self-conscious act 
which the consciousness can will and later reflect through memory are phenomenology accounted in the triadic structure; especially its (b) part. This shows that Husserlian self is not a metaphysical substance. The triadic structure of Husserl's transcendental self as 'ego-person-monad' respectively admit an interpretation as: (a) the subject who is the actpole which wills and decide and act (as a subject-centered reading might render), but there is more to it, i.e. part-(b)which is its temporal formation as 'style' and non-thematic, and finally part-(c) which corresponds to this act-pole as being concrete particular individual possessing this particular body(Heinämaa, 2011). This analysis is carried out predominantly within the genetic model of Cartesian Meditations insofar as it admits an extension to the genetic method of Crisis, and since much of this was a further continuation of Husserl's phenomenology of time (1991), we can see that the subject centered reading by many Husserl's critics, Judith Butler in particular, is mistaken.

\section{Conclusions}

This study has argued that feminist critique of reason is right in some aspects but wrong in others. It is right in identifying the existence of an oppressive dimension of reason. But it is wrong in equating reason with this oppressive dimension. Insofar as it is right, it is part of the reason itself. However, insofar it is wrong; a new possibility of critiquing reason has been argued from phenomenology. This is achieved by arguing how a phenomenological possibility of critiquing reason, which is called phenomenology of reason, can be developed from Husserl's transcendental phenomenology such that it does not lend itself to the feminist criticism as being the masculine or oppressive dimension of reason. This shows that phenomenological perspective, as developed in this study, is significantly relevant for feminist critical project in general and feminist critique of reason in particular.

\section{End Notes}

1. Docekal (1999) also take the task of outlining the main tenets of the first three critiques. However, as will become amply clear from what follows, Docekal's analysis itself is mistaken in some very significant aspects which are the consequence of her Kantian transcendentalist methodology.

2. By labeling Irigaray's and Butler's thinking "as what strongly involves hermeneutic and phenomenological underpinnings," authors are not calling them hermeneutic phenomenologists, but only that their works (especially the ones cited in this study) possess hermeneutic phenomenological prospects. That such is the case; we refer our reader to the pioneering works of Annemie Halsema in this theme; in particular, cf. (Halsema, 2011).

3. Pure mathematics is another such discipline, one just has to follow how many Abel prizes or Fields medals have been awarded to women. Only one woman-Maryam Mirzakhani- has been able to secure the most prestigious award, Fields Medal, to this day. This is the case when there are around 60 Fields Medalists in total and still counting! 
Same is the case with another most prestigious award in the field of mathematics, i.e. Abel prize. No woman has been awarded this prize as yet. People usually don't know that mathematicians are not awarded Nobel Prize. If a mathematician is awarded a Nobel Prize, it must be because of his contribution in physics (or in some other field listed within the scope of Nobel Prize) and not in mathematics as such.

4. In the project of feminist critique of reason as pursued by Docekal (1999), we don't find this axiom as such. But this is what Docekal also implicitly adheres to. For there is no disagreement between Docekal and the other three feminists that such is the case. The disagreement is primarily grounded in the methodology and the ethical consequences of these methodologies. For instance, Docekal does not reject Irigaray's claim that occidental reason has connotations of masculinity, for it has undermined women by stereotyping them as emotional. It is her philosophical method which, according to Docekal, is responsible for over drawn objections to the same reason, since her critical method has only led her to a particular aspect of the same reason, which Docekal has characterized as instrumental rationality. In other words, Docekal's main objection is that each of these three feminists has only been able to cover a particular aspect of that reason and that each such aspect does depict how the same reason is responsible for the subjugation of women. But there are other aspects, which these thinkers missed. This is what Docekal is primarily trying to supplement. Docekal is not rejecting the reason's claim to unity or universality. This is why; her feminist thinking is quite conservative as compared to the rest of the three.

5. Cf. introduction and the second essay part 1 (Keller, 1995)

6. Hafiz Syed Husain (2018) has already argued how this is the case in case Kant's third critique.

7. There was another way with which the same hypothesis could have been reached. First author was intimated this by Prof. Dr. Abdul Rahim Afaki from department of philosophy university of Karachi (who also supervised first author's PhD thesis). His argument roughly went as follows. Suppose that feminist critique is right in its claim that reason is equal to MD. Then there is nothing that could save feminism-in particular feminist critique of reason-from becoming logically self-defeating, for it has used arguments, in one way or another, to convince that reason is masculine. However, we did not follow this way of thinking in this study for it apparently sounds simple and straightforward but involves interpretive subtleties of its own. Also if hypothesis is reached this way, then the corresponding research question would be totally different and a new direction will be correspondingly opened up.

8. Cf. (Hintikka, 1995), (Philipse, 1995), (Zahavi, 2003a) \& (Held, 2003) for an introduction to Husserl's phenomenological method. For a comprehensive introduction to Husserl, cf. (Smith D. W., 2007).

9. In what follows, there will be three different designations for reason: reason, 'reason' and 'Reason.' Reason without quotations refers to what ordinary language (including 
scientific disciplines) has to offer in context of understanding reason; 'reason' corresponds to the same reason (without quotes) under phenomenological epoché, and finally 'Reason' as what we-in this phenomenological investigation-are primarily after.

10. (Husserl, 1983, pp. 57ff, $<54>$ ff), (Husserl, 1960, pp. 20ff, $<60>$ ff )

11. Cf. (Smornyski, 1977). We also refer to (Husain, Hermeneutical Reflections on Mathematical Significance, Accepted for publication) for how mathematical reason can be accounted which is non-idealist type.

12. For someone not an expert in phenomenology, this may be a serious methodological mistake. For how could one count something the part of that thing to which it claimed to be opposite in some of the most significant aspects without providing a valid justification? As far as such a person is concerned, this should be an instance of circular reasoning, for we apparently have already presumed what we claimed to justify! But this is a sheer instance of misconstruing the phenomenological method of investigation. This paper does not aim to explicate the method of Husserlian phenomenology. On contrary, it pretty much assumes it as its background. However, a brief account is presented, only inasmuch as it helps in removing the objection. According to Husserlian phenomenology, the method of phenomenology involves epoché as its first step (Husserl 1960, pp. 56ff; Zahavi, 2003a). This involves getting rid of natural attitude which involves all kinds of presumptions about the world (in particular about the object or phenomenon to which we are after). For instance, anyone phenomenologically investigating the human phenomenon of perception must first bracket all presumptions about the nature of existence of the things in the world (including the world itself) which correlates with the act of perception as object of perceptions: for instance, whether objects (or world is) are material, spiritual, ideal, etc. This is why a "phenomenology of perception' would take equally seriously all claims to perceptual reality whether made some shaman (even already in trance) or by some cognitive psychologist even if they are found to be in serious opposition to each other.

13. Husserl clearly distinguished his phenomenology-whether in the version of transcendental or eidetic - as the science of 'pure possibilities' from all other sciences which are concerned with 'actualities.' Latter works with causality, former with intentionality (Husserl, Cartesian Meditations: An Introduction to Phenomenology, 1960, pp. 69-72)

14. Cf. for instance: (Husserl, Logical Investigations-I, 2001, pp. 166, 177-179), (Husserl, Cartesian Meditations: An Introduction to Phenomenology, 1960, p. 48). There are many ways with which Husserlian phenomenological method can be pursued, for instance, the one outlined in Husserl's Logical Investigations (2001), or the one in Ideas-I (1983), or the one as in Cartesian Meditations (1960), and finally the one from one of his latest works Crisis (1970). It is a matter of much debate among Husserlian scholars that if all of them are to be considered introductions to Husserlian phenomenology (as first of the three texts were called so by Husserl 
himself) then how to account the internal differences between these texts? We can divide Husserl's works into 'early Husserl' (the one who wrote Logical Investigations), the middle period (of Ideas-I through On Phenomenology of Internal-Time Consciousness (1991)) and the later period from Cartesian Meditations through Crisis. It is a strong conviction of the first author, that although there are significant internal differences between these texts, however, Husserl's phenomenology can be reconstructed possessing a singular theme right from the first initiation till the last one such that the idealistic transcendental turn characterized by both Ideas-I and Cartesian Meditations can be reconciled with later Husserl's phenomenology of life-world. However, this is a huge task and is currently only a proposal beyond the scope of this paper.

15. The actual statement of the principal is as follows: "that every originary presentive intuition is a legitimizing source of cognition, that everything originarily (so to speak, in its "personal" actuality) offered to us in "intuition" is to be accepted simply as what it is presented as being, but also only within the limits in which it is presented there." (Husserl, Ideas Pertaining to a Pure Phenomenology and to a Phenomenological Philosophy, 1983, p. 44).

16. This is why Husserl's idealism is not one of Cartesian kind. For Husserl, consciousness is not separate from the world. It always has the world as its object. This is why there is no subject-object dichotomy.

17. Right now we are assuming as many Husserlian scholars also believe that intentionality is the characterizing property of consciousness, despite the fact that some of Husserl's critics have found counter-examples to this characterization. For reasons, cf. (Smith A. D., 2003, p. 72ff). For a concise detail of the account of intentionality, cf. (Drummond, 2003)

18. Again, there are disagreements among Husserlian scholars on this matter too. Some regards - including authors - that every meaning-intention involves empty intentions. Even in a self-fulfilling intuition, there exists an empty intention (Husserl, Logical Investigations-II, 2001, p. 218ff).

19. Here again, we have denoted natural time, i.e., both ordinary time of everyday-life commons-sense perception and the time of the sciences (both physical and historical) as 'time'; and the time-as-thing-itself which is the constitutive principal as 'Time.'

20. Cf. (Husserl, On the Phenomenology of the Consciousness of Internal Time, 1991) for the detail, or cf. (Zahavi, 2003a \& 2003b) for a concise commentary.

21. ${ }^{1}$ The term 'natural' in standard phenomenological vocabulary corresponds to the aspect of consciousness which is pre-phenomenological. That is to say, it corresponds to both the ordinary everyday-life consciousness and the scientific consciousness of research and scholarly academia. It has to be contrasted with 'transcendental' which corresponds to the consciousness affected by the transcendental attitude. For instance, in natural attitude, 'reason' corresponded to both, the faculty of justification or the account of justification; whether sought 
through ordinary common-sense criticism or through any particular science. In particular, 'time' is 'reasonably' accounted in everyday-life by ordinary perception through clocks and calendar; as if 'time' has an independent existence and things happen in time. In physics, time is not independent but itself a dimension of physical structure of the cosmos.

22. Although she does not critique Husserl's transcendental philosophy (Butler, 1988) as such but her allusion to Husserl is clear from her remarks appearing right after Husserl's name being mention: "Though phenomenology sometimes appears to assume the existence of a choosing and constituting agent prior to language (who poses as the sole source of its constituting acts), there is also a more radical use of the doctrine of constitution that takes the social agent as an object rather than the subject of constitutive acts." The first part till "... (...its constituting acts)" refers to Husserl, whereas the latter part "there is also....rather than the subject of constitutive acts" refers to Merleau-Ponty.

23. Cf. (Stoller, 1984) for detail of this distinction.

24. Besides this, one can also cite (CAPUTO, 1984)and for a radically insightful reading of Husserl in context of how hermeneutic possibilities were already part of Husserl's phenomenology of time, in particular, as further expounded in (Husserl, 1960).

25. For Irigaray, bodily experiences are prior to any thematizations by disciplines. For instance, she writes in To Be Two (2001, p. 21): "In so far as I belong to a gender, my body already represents an objectivity for me. . . . Belonging to a gender allows me to realize, in me, for me - and equally towards the other-a dialectic between subjectivity and objectivity which escapes the dichotomy between subject and object." Also, cf. (Irigaray, This Sex Which is Not One, 1985) for examples of feminine experience of touch.

\section{Bibliography}

Alcoff, L. M. (2006). Visible Identities: Race, Gender, and the Self. New York: Oxford University Press.

Butler, J. (1988). Performative Acts and Gender Constitution: An Essay in Phenomenology and Feminist. Theatre Journal, vol.40:4, pp.519-531.

Butler, J. (1993). Bodies that Matter: On the Discursive Limits of "Sex". New York, London: Routledge.

Butler, J. (1997). The Psychic Life of Power: Theories of Subjection. Stanford, California: Stanford university Press.

Butler, J. (2005). Giving an Account of Oneself. New York: Fordham University Press. 
CAPUTO, J. D. (1984). Husserl, Heidegger and the Question of a Hermeneutic Phenomenology. Husserl Studies, pp.157-178.

Drummond, J. J. (2003). The Structure of Intentionality. In D. Welton (Ed.), The New Husserl: A Critical Reader, Bloomington \& Indiana Polis: Indiana University Press, pp.65-92.

Fisher, L. (2011). Gendering Embodied Memory. In Time in Feminist Phenomenology, Bloomington, Indianapolis: Indiana University Press, pp.91-110.

Halsema, A. (2011). The Time of the Self: A Feminist Reflection on Ricoeur's Notion of Narrative Identity. In Time in Feminist Phenomenology, Bloomington, Indianapolis: Indiana University Press, pp.111-131.

Heinämaa, S. (2011). Personality, Anonymity, and Sexual Difference: The Temporal Formation of the Transcendental Ego. In Time in Feminist Phenomenology, Bloomington, Indiana: Indiana University Press, pp.41-59.

Held, K. (2003). Husserl's Phenomenological Method. In D. Welton (Ed.), The New Husserl: A Critical Reader, Bloomington \& Indianapolis: Indiana University Press.

Hintikka, J. (1995). The Phenomenological Dimension. In B. Smith, \& D. W. Smith (Eds.), The Cambridge Companion to Husserl, New York: The Cambridge University Press, pp.78-105.

Husain, H. S. (2018). Schleiermacher's Universal Hermeneutics and the Problematics of Rule-Following. Science \& Philosophy, vol.6:1, pp.3-14.

Husain, H. S. (Accepted for publication). Hermeneutical Reflections on Mathematical Significance. Philosophical Readings.

Husserl, E. (1960). Cartesian Meditations: An Introduction to Phenomenology. (D. Cairns, Trans.) Hague: Martinus Nijhof.

Husserl, E. (1970). The Crisis of the European Sciences and Transcendental Philosophy. (D. Carr, Trans.) Evanston: Northwestern University Press.

Husserl, E. (1983). Ideas Pertaining to a Pure Phenomenology and to a Phenomenological Philosophy. (F. Kersten, Trans.) Hague: Martinus Nijhof. 
Husserl, E. (1991). On the Phenomenology of the Consciousness of Internal Time (Vol. IV). (J. B. Brough, Trans.) Dordrechts: Kluwer Academic Publishers.

Husserl, E. (2001). Logical Investigations-I (Vol. 1). (J. N. Findlay, Trans.) London: Routledge.

Husserl, E. (2001). Logical Investigations-II (Vol. 2). (J. N. Findlay, Trans.) London: Routledge.

Irigaray, L. (1985). This Sex Which is Not One. (C. Porter, \& C. Burke, Trans.) New York: Cornell University Press.

Irigaray, L. (2001). To Be Two. (M. M. Rhodes, \& M. F. Cocito-Monoc, Trans.) New York: Routledge.

Keller, E. F. (1995). Reflections on Gender and Science. New Haven, London: Yale University Press.

Kelly, S. D. (2003). Edmund Husserl and Phenomenology. In Blackwell Guide to Continental Philosophy (pp. 112-142). Maldin, Oxford, Melbourne: Blackwell Publishing.

Merleau-Ponty. (2005). Phenomenology of Perception. (C. Smith, Trans.) London, New York: Routledge.

Nagl-Docekal, H. (1999). The Feminist Critique of Reason Revisited. Hypatia, vol.14:1, pp.49-76.

Philipse, H. (1995). Transcendental Idealism. In B. Smith, \& D. W. Smith (Eds.), The Cambridge Companion to Husserl (pp. 239-322). New York: Cambridge University Press.

Ricoeur, P. (1991). Life in Quest of Narrative. In On Paul Ricoeur: Narrative and Interpretation (pp. 20-33). London, New York: Routledge.

Sandmeyer, B. (2009). Husserl's Constitutive Phenomenology: its problems and promise. New York: Routledge.

Smith, A. D. (2003). Husserl and the Cartesian Meditations. London, New York: Routledge. 
Smith, D. W. (2007). Husserl. London \& New York: Routledge.

Smornyski, C. (1977). The Incompleteness Theorems. In J. Barwise (Ed.), Handbook of Mathematical Logic (pp. 821-866). Amsterdam: Elsevier.

Steinbock, A. J. (1995). Home and Beyond: Generative Phenomenology after Husserl. Evanston, Illinois: Northewestern University Press.

Stoller, R. J. (1984). Sex and Gender: The Development of Masculinity and Femininity. London: Karnac Books.

Zack, N. (2007). Can Third Wave Feminism Be Inclusive? Intersectionality, Its Problems, and New Directions. In L. M. Alcoff, \& E. F. Kittay (Eds.), The Blackwell Guide to Feminist Philosophy (pp. 193-210). Massechusset, Oxford, Victoria: Blackwell Publishing.

Zahavi, D. (2003a). Husserl's Phenomenology. Stanford: Stanford University Press.

Zahavi, D. (2003b). Inner Time-Consciousness and Pre-reflective Self-awareness. In D. Welton (Ed.), The New Husserl: A Critical Reader (pp. 157-180). Bloominigton $\&$ Indianapolis: Indiana University Press.

Hafiz Syed Husain is Ph.D Scholar in the Department of Philosophy University of Karachi, Karachi, Pakistan.

Dr. Mustafa Hyder is an Assistant Professor in the Department of Public Administration, University of Karachi, Karachi, Pakistan.

Dr. Mariam Sultana is an Assistant Professor in the Department of Mathematical Sciences, Federal Urdu University of Arts, Science \& Technology, Karachi, Pakistan. 